\title{
Auditory Cortex Neurons: Primary Culture and Ion Channel Activity in Rat
}

\author{
ERNEST J. MOORE, ${ }^{1,2}$ DEANNE B. HALL ${ }^{1,2}$ and TOSHIO NARAHASHI ${ }^{2}$ \\ From the ${ }^{1}$ Auditory Neuroscience Laboratory, Department of Audiology and Speech Sciences, Michigan State University, East Lansing, \\ MI 48824-1212, and ${ }^{2}$ Department of Molecular Pharmacology \& Biological Chemistry, Northwestern University Medical School, Chicago, \\ IL 60611-3008 USA
}

\begin{abstract}
Moore EJ, Hall DB, Narahashi T. Auditory cortex neurons: primary culture and ion channel activity in rat. Acta Otolaryngol (Stockh) 1995; 115: 776-782.

We have developed a primary dissociated cell culture of the fetal (E17) and post-natal (P0-P10) rat auditory cortex. Pyramidal and non-pyramidal cells had a mean cross-sectional diameter of $12.73 \pm 1.80 \mu \mathrm{m}$ (mean \pm S.D., $n=25)$ and $17.58 \pm 1.67 \mu \mathrm{m}$ (mean \pm S.D., $n=10$ ), respectively, measured at 6 days in culture. These cells were viable for as long as 18-21 days. They expressed voltage-gated sodium and potassium channel currents as early as one day in culture, and at various phases in cell culture. Sodium current, activated at membrane potentials more positive than $-60 \mathrm{mV}$, displayed fast activation and inactivation kinetics. Fifty percent inactivation of sodium channels occurred at a pre-pulse potential of $-63 \mathrm{mV}$. Delayed rectifier potassium channels were activated at potentials positive to $-40 \mathrm{mV}$. Large hyperpolarizing constant current pulses elicited anode break action potentials, and large depolarizing constant current pulses exhibited rectification indicative of the delayed rectifying potassium channel activity. Key words: cell culture, patch-clamp, sodium channel, potassium channel.
\end{abstract}

\section{INTRODUCTION}

The auditory cortex is an important part of the vertebrate auditory sensory integration system. In the rat, it is located in the posterolateral neocortex (1). The auditory cortex has been extensively investigated using anatomical (cytoarchitecture, topographical organization, connectivity) and neurophysiological techniques, the latter using evoked potential recordings and single-unit mapping protocols (2). To date there have been no investigations of molecular ionic currents of dissociated auditory cortex neurons using patch-clamp techniques. In the present study, a primary cell culture of the rat auditory cortex was developed, and whole-cell voltage-clamp and currentclamp techniques were employed. We report here unique features of dissociated auditory cortex neurons grown in cell culture, and present characteristics of sodium and potassium currents (3).

\section{MATERIALS AND METHODS}

\section{Dissociated cell culture}

Rat auditory cortex $(1,4,5)$ located on the postereolateral surface and depths of the left temporal cortex (TE1, TE2 and TE3, 1) was dissected $(\sim 2 \times 2 \times 1$ $\mathrm{mm}$, using the bregma, central sulcus and major blood vessels as land marks) from rat pups (Sprague-Dawley, E17 and P0-P10). The pups were anesthetized with methoxyflurane followed by rapid decapitation and thoracotomy. Auditory cortical tissue was isolated and incubated using trypsin $(2.0 \mathrm{mg} / \mathrm{ml}$, type VI, Sigma Chemical Co., St. Louis, MO) in $\mathrm{Ca}^{2+}$ $\mathrm{Mg}^{2+}$-free phosphate-buffered saline solution (PBS) for $23-30 \mathrm{~min}$ at $37^{\circ} \mathrm{C}$. Some cultures were prepared without using any enzymatic treatment. When enzymes were used, they were followed by rinsing three times using PBS and Dulbecco's Modified Eagle's Medium (DMEM) supplemented with glucose $(6 \mathrm{mg} /$ 1), Ham's F12 supplement ( $50 \mathrm{ml}$, Sigma, St. Louis), $10 \%$ heat-inactivated fetal calf serum (Northwestern University Cancer Center, Chicago, IL) and antibiotics of $20 \mathrm{U}$ penicillin/20 ng streptomycin per ml. Following the third wash was added a mixture of DNAse $\left(1.5 \mathrm{mg} / \mathrm{ml}\right.$, Sigma) and $\mathrm{MgSO}_{4}(2.5 \mathrm{mg} / \mathrm{ml}$, Matheson, Coleman \& Bell, Norwood, OH). The cells were dissociated mechanically by pipetting the media using a fire-polished Pasteur pipette. The cell suspension was plated onto confluent cortical glial cell feeder layer cultures. The cover-slips $(12 \mathrm{~mm}$, Costar, Cambridge, MA) had been previously coated with poly-L-lysine $(0.2 \mathrm{mg} / \mathrm{ml})$ and were placed in plastic 6-well cell culture clusters. Two $\mathrm{ml}$ of the cell suspension/culture media ( $100 \mathrm{~K}$ cells/ml) were added to each of the 6-wells. The cells were cultured in DMEM at $37{ }^{\circ} \mathrm{C}$ in a $5 \% \mathrm{CO}_{2}, 95 \%$ air atmosphere for as long as they survived. The media were not changed during the period of survival, but nerve growth factor ( $25 \mathrm{ng} / \mathrm{ml}$, Sigma) was added to several cultures in which post natal animals were used.

\section{Electrical recordings}

The whole-cell variation of the patch-clamp technique was used to record ionic currents under voltageclamp conditions (6). Patch pipettes made of borosilicate glass capillary tubes $(0.8-1.1 \mathrm{~mm}$ i.d, Kimble Products, Vineland, NJ) were pulled to have resistance of 1-3 Mohms. Voltage-clamp command pulses of $20 \mathrm{~ms}$ were applied through the pipette, and 
a pellet $/ 3.0 \mathrm{M} \mathrm{KCl-agar}$ bridge was used as a reference electrode. A liquid junction potential of $-3 \mathrm{mV}$ was corrected. No series resistance compensation was used, but leak and transient subtraction was included by the use of the $\mathrm{P}+\mathrm{P} / 4$ method (7). Membrane currents passing through the pipette were recorded by a current-to-voltage converter consisting of a 500 Mohm feedback resistor and amplifier (Axopatch, 1B, Axon Instruments, Burlingame, CA). Data were stored on disks using a minicomputer (PDP-11/73, Digital Equipment Corp., Maynard, MA) in combination with a microcomputer (System 325, Dell Computer Corp., Austin, TX). For current-clamp experiments, constant hyperpolarizing and depolarizing current pulses of $100 \mathrm{~ms}$ duration with a range of -200 to $+200 \mathrm{pA}$ were employed. Experiments were performed in accordance with the principles of the Declaration of Helsinki.
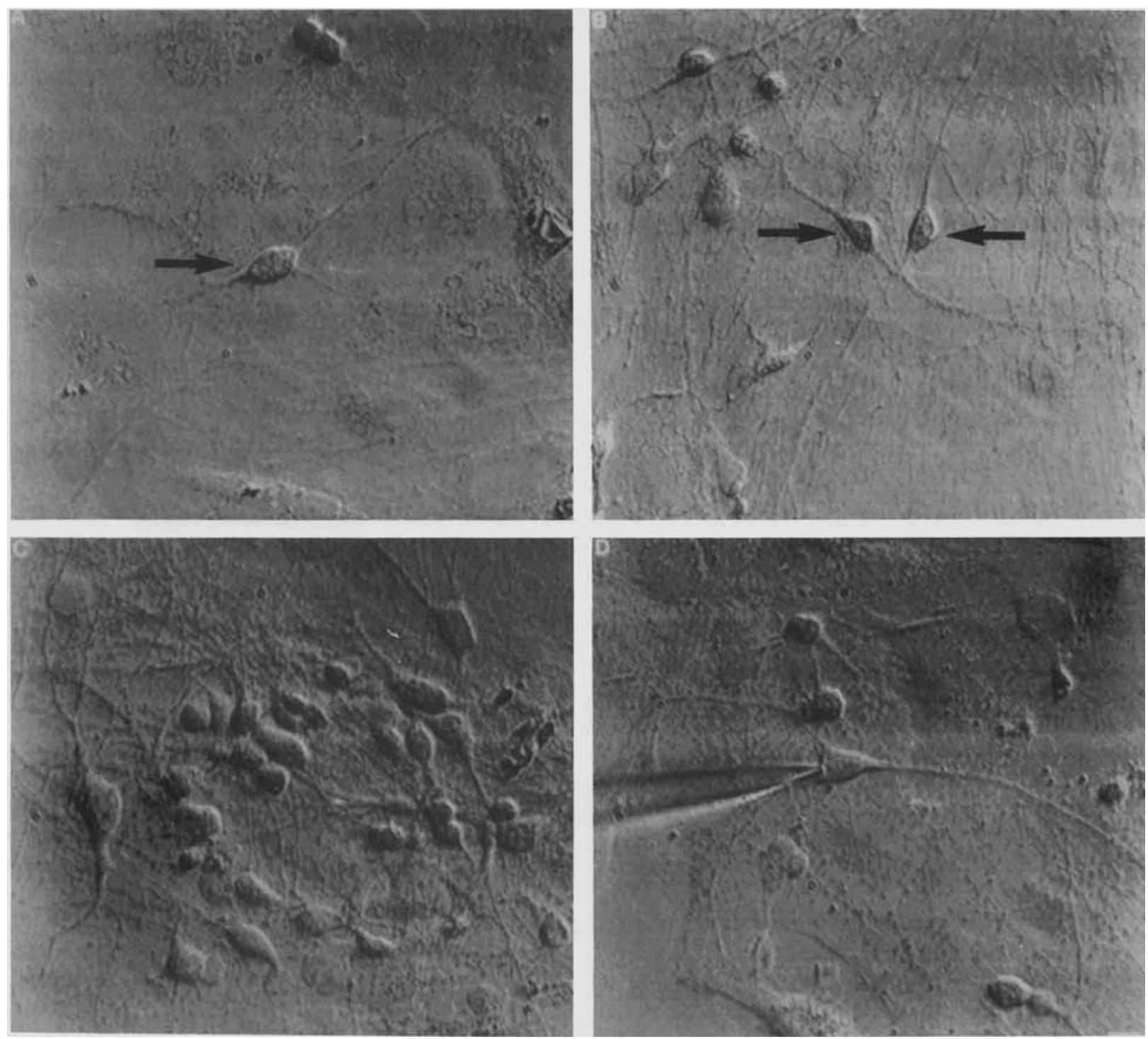

Fig. 1. Photomicrographs of rat (E17) auditory cortex neurons five days in culture using differential interference contrast images (Hoffmann optics). Cells were fixed for 20 min using PBS containing 4\% paraformaldehyde and $5 \%$ sucrose, washed three times with PBS, and allowed to equillibrate at room temperature for $10 \mathrm{~min}$. (A) A pyramidal cell (see arrow) with apical and basilar dendrites located in the center of the field. (B) Two bipolar pyramidal cells (arrows) located in close proximity to each other with several other pyramidal and non-pyramidal cells off to the left of the central field. (C) An aggregate of pyramidal (pyramid-shaped) and non-pyramidal (not pyramid-shaped) cells of different size and length of neurites. (D) A pyramidal cell with microelectrode in close proximity to the cell. A few non-pyramidal cells are located also in the field. All cells were plated on a glial substrate, and were obtained from the cortex of P1-P3 rat pups. Calibration is $10 \mu \mathrm{m}$ for all panels. 


\section{Solutions}

The external solution consisted of (in $\mathrm{mM}$ ): $\mathrm{NaCl}$ $140, \mathrm{KCl} 5.0, \mathrm{CaCl}_{2} 2.5, \mathrm{MgCl}_{2}$ 2.0, HEPES-acid 5.5, HEPES-Na 4.5, glucose $10, \mathrm{pH}, 7.4$, with osmolarity of 290-310 mOsms. Tetrodotoxin (TTX) $(0.5 \mu \mathrm{M})$ was used to suppress sodium current. Tetraethylammonium chloride (TEA-Cl) $(25-50 \mathrm{mM})$ was used to suppress potassium current. Internal solutions consisted of (in $\mathrm{mM}$ ): $\mathrm{CsCl} 110$ (or $\mathrm{KCl}$ for potassium current recording), $\mathrm{MgCl}_{2} 2.0, \mathrm{CaCl}_{2}$ 1.0, HEPESacid 10, EGTA 11, ATP-Mg 2.0, pH, 7.4, and osmolarity of $290 \mathrm{mOsms}$. All experiments were conducted at a room temperature of $22-23^{\circ} \mathrm{C}$.

\section{RESULTS}

Fig. 1 shows a photomicrograph of auditory cortex cells, isolated from an E17 rat, at 5 days in culture. This illustration shows an isolated pyramidal cell (see arrow, Fig. 1A), several pyramidal (see arrows) and non-pyramidal cells (Fig. 1B), or aggregates of pyramidal and non-pyramidal cells (Fig. 1C). A glass micropipette was placed in close proximity to a pyramidal cell as illustrated in Fig. 1D. Fig. 1 illustrates also nerve fiber outgrowth for 5 days in culture. With our technique of cell culture, short residual neurites or outgrowth was observed as early as at the time of plating $(4-7 \mu \mathrm{m}), 40-50 \mu \mathrm{m}$ at $4 \mathrm{~h}$ in culture, and $60-90 \mu \mathrm{m}$ after $28 \mathrm{~h}$ in culture. Survival time of cells without granularity was, on the average, about $18-21$ days, but some cultures have remained viable for more than 30 days. Some pyramidal and non-pyramidal shapes could be distinguished within hours after plating and the extent of their growth could be followed over time, as they continued to undergo growth changes with proliferation of neurites for several days. After about $4 \mathrm{~h}$ in culture, one could distinguish rounded stellate cells with their spiny extensions, or pyramidal cells with their characteristic pyramid-like shape, exhibiting an apical and a basilar

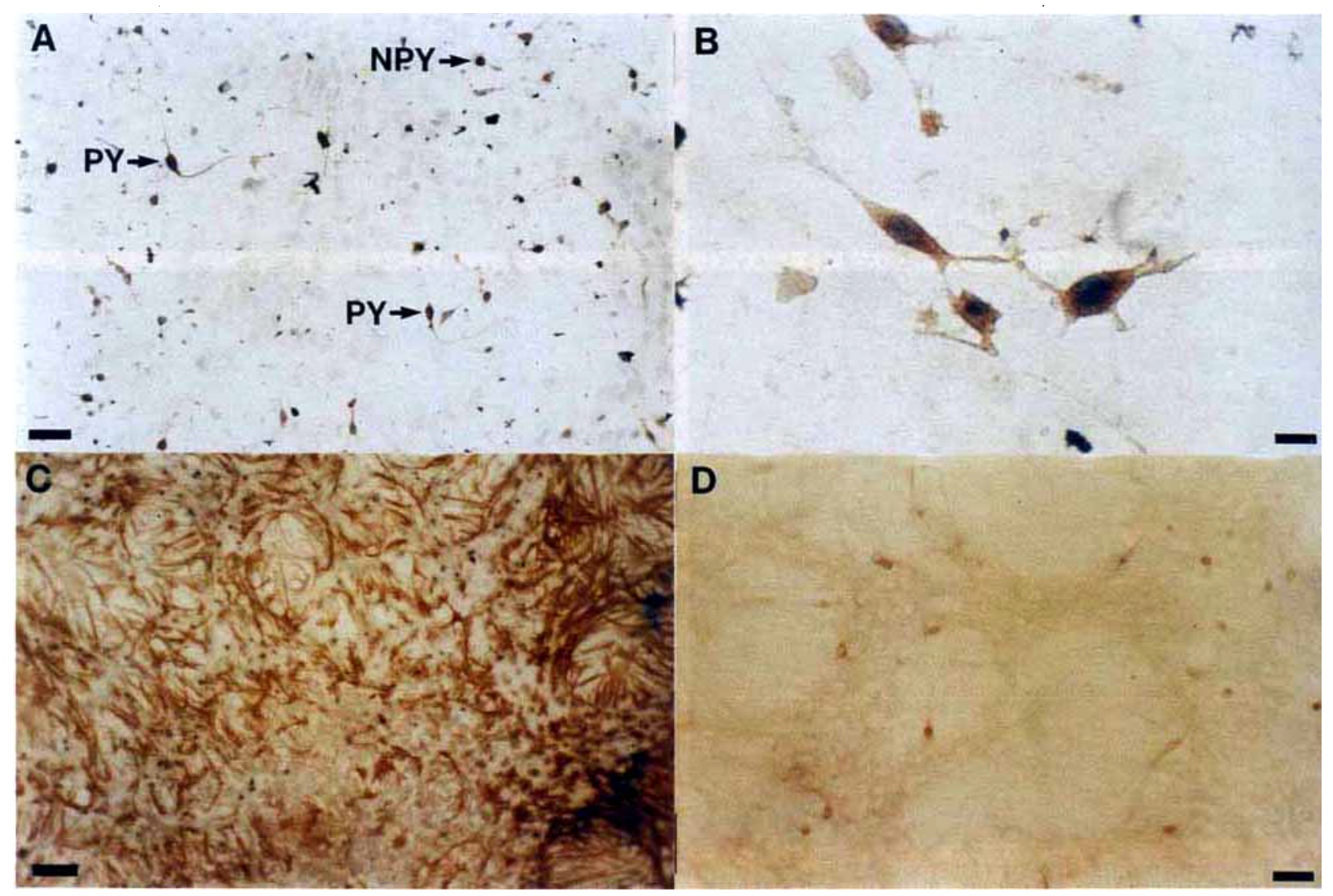

Fig. 2. Photomicrographs of rat (E17) auditory cortex neurons 11 days in culture using techniques of immunocytochemistry. (A) Bright field images of several pyramidal (PY-arrows) and non-pyramidal (NPY-arrows) neurons using neuron specific enolase. (B) Neuron specific enolase staining, with counterstain of hematoxylin. Several pyramidal cells exhibit staining for neuron specific enolase as well as hematoxylin stain (blue color) for nuclei. (C) Glial substrate stained with glial fibrillary acidic protein, and counterstained (black dots) using hematoxylin. (D) A negative control which does not exhibit staining for neuron specific enolase (for neurons) nor glial fibrillary acidic protein (for glia). Calibration is $40 \mu \mathrm{m}$ for $\mathrm{A}$, 10 $\mu \mathrm{m}$ for $\mathrm{B}$, and $40 \mu \mathrm{m}$ for $\mathrm{C}$ and $\mathrm{D}$. 


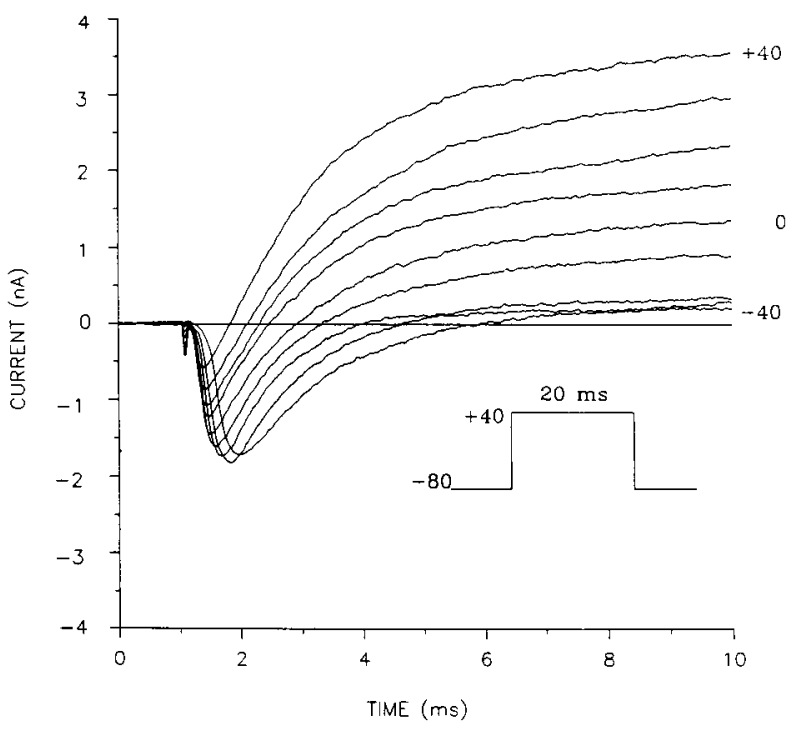

Fig. 3. Whole-cell voltage-clamp of left auditory cortex pyramidal cell of rat in primary culture. Transient inward sodium current and slow outward potassium current associated with steps to potentials ranging from $-40 \mathrm{mV}$ to +40 $\mathrm{mV}$ from a holding potential of $-80 \mathrm{mV}$. The family of curves were obtained from a pyramidal cell $(11.88 \mu \mathrm{m})$ from an E17 rat at 10 days in culture. The inset shows the pulse protocol.

dendrite. Cell size at 6 days in culture (E17) for pyramidal cells was $12.73 \pm 1.80 \mu \mathrm{m}$ (mean \pm S.D., $n=25)$, and for non-pyramidal cells was 17.58 $\pm 1.67 \mu \mathrm{m}$ (mean \pm S.D., $n=10)$. When placed in the external recording media, cells remained viable for up to 1 to $2 \mathrm{~h}$ without visible deterioration.

Fig. 2 displays immunocytochemistry of a selected group of cells at 11 days in culture (E17). The cells were stained using neuron specific enolase which revealed the neuronal population (Fig. 2A), counterstained using hematoxylin which stained the nuclei of the cells (Fig. 2B), and further stained using glial fibrillary acidic protein (plus hematoxylin) for the glial background on which these cells were plated (Fig. 2C). The negative control (Fig. 2D) in which the primary sera was omitted shows the absence of immunostaining. Fig. 2A shows specific staining for pyramidal (see PY-arrow) and non-pyramidal (see NPY-arrow) cells. Fig. 2B reveals a different field from Fig. 1B of three pyramidal cells in the center of the field, and one cell off center, with clearly identifiable nuclei exhibiting hematoxylin staining. Fig. $2 \mathrm{C}$ shows the enhanced glial background (which was treated with arabinocide, 3 days in culture), but in addition, the darkened spots represent the uptake of hematoxylin by the nuclei of auditory cells without neuron specific enolase staining. The negative control (Fig. 2D) clearly attests non-staining of neuronal structures and glia.

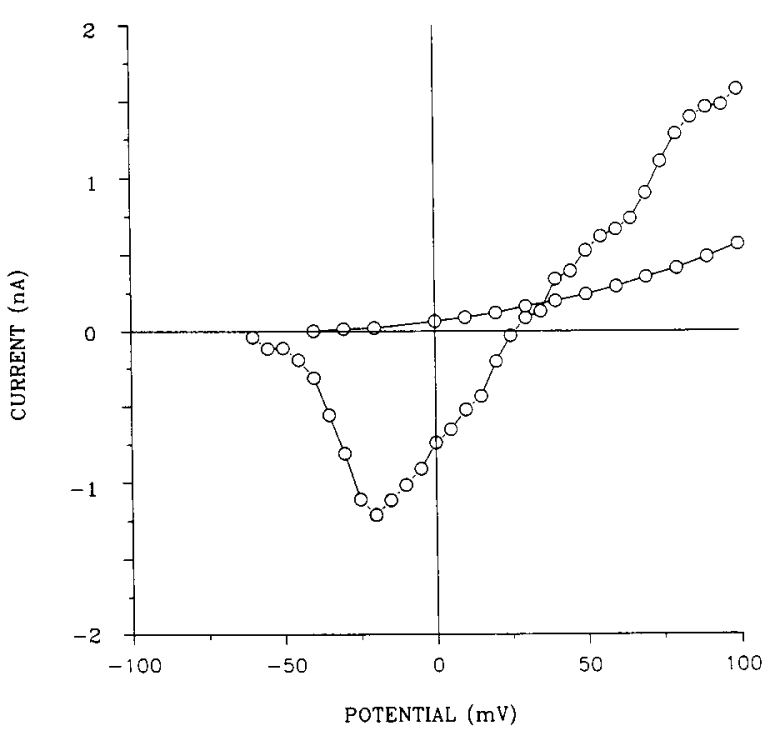

Fig. 4. Current-voltage relations for transient inward sodium currents and outward potassium currents associated with step depolarizations from a holding potential of -80 $\mathrm{mV}$. The data were obtained from a P5 rat neuron of 9.50 $\mu \mathrm{m}$ maintained in short-term culture.

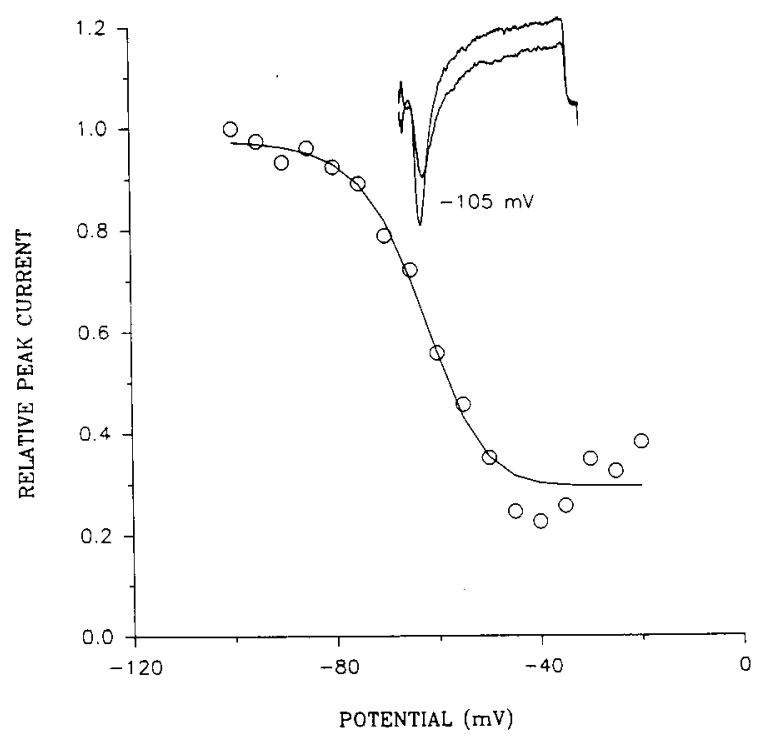

Fig. 5. Mean steady-state sodium channel inactivation curve obtained for three cells. The amplitudes of transient sodium currents associated with step depolarizations ranging from $-110 \mathrm{mV}$ to $0 \mathrm{mV}$ following $1 \mathrm{~s}$ prepulses to various potentials are normalized to the maximal value at $-100 \mathrm{mV}$, and are plotted as a function of the prepulse potentials. The slope of the curve was $-10.72 \mathrm{mV}$ and the half-maximal point was $-63 \mathrm{mV}$ and is based on maximum minus the minimum non-inactivating sodium component. The inset shows current records to step depolarizations at $-105 \mathrm{mV}$ and $-55 \mathrm{mV}$. 


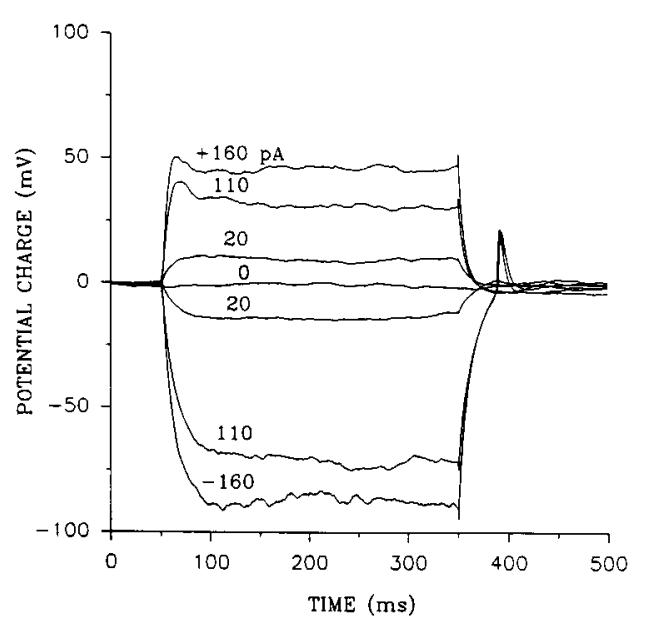

Fig. 6. Potentials evoked by $100 \mathrm{~ms}$ constant current pulses at $+160 \mathrm{pA},+110 \mathrm{pA},+20 \mathrm{pA}, 0 \mathrm{pA},-20 \mathrm{pA},-110 \mathrm{pA}$ and $-160 \mathrm{pA}$. Same cell as Fig. 3. The small amplitude of approximately $20 \mathrm{mV}$ for the anode-break action potentials are probably due to a genrator site located remotely from the cell body. The asymmetry between hyperpolarizing and depolarizing potentials is indicative of the opening of delayed rectifier potassium channels during depolarization.

Electrophysiologic data obtained from one of the auditory cortical neurons are displayed in Fig. 3. Fig. 3 shows sodium current and potassium current associated with step depolarizations from $-40 \mathrm{mV}$ to +40 $\mathrm{mV}$ using a holding potential of $-80 \mathrm{mV}$ in a pyramidal cell dissociated from an E-17 rat at 10 days in culture. These currents were observed in cells as early as one day in culture and at various phases of culture. Sixteen cells were successfully tested with similar results. Neither TTX nor TEA-Cl was present in the external solution. The inward ionic currents could be reversibly blocked by $0.5 \mu \mathrm{M}$ TTX and the outward ionic currents could be blocked by 25 to 50 $\mathrm{mM}$ TEA-Cl (data not shown), indicating that the inward and outward currents were carried through the sodium and potassium channel, respectively. No TTXresistant sodium channel currents were observed.

The current-voltage relations for peak transient sodium current and potassium current measured at 8 $\mathrm{ms}$ after the beginning of depolarization pulses are plotted as a function of the test potential in Fig. 4. A P5 rat neuron $(9.5 \mu \mathrm{m})$ in short-term culture was used. The sodium current was activated at membrane potentials more positive than $-60 \mathrm{mV}$, peak current occurred at $-20 \mathrm{mV}$ and the reversal potential was estimated to be $+25 \mathrm{mV}$. The potassium current was activated at $-40 \mathrm{mV}$ and increased in amplitude with increasing depolarization and did not inactivate.

The amount of sodium current that was available for activation was investigated (Fig. 5). The steadystate voltage dependence of sodium channel inactiva- tion was measured using a two-pulse protocol with 1 $\mathrm{s}$ pre-pulses ranging from $-110 \mathrm{mV}$ to $0 \mathrm{mV}$ and a test pulse of $10 \mathrm{~ms}$ stepped to $0 \mathrm{mV}$. The steady-state inactivation curve representing the average of three cells could be fit with a sigmoid curve with a slope of $-11 \mathrm{mV}$ and $50 \%$ inactivation occurred at a prepulse potential of $-63 \mathrm{mV}$.

Fig. 6 displays potentials of cultured rat auditory cortical neurons (E17 rat, pyramidal cell, 10 days in culture) to hyperpolarizing and depolarizing constant current pulses. Small depolarizing and hyperpolarizing currents of $20 \mathrm{pA}$ intensity evoked symmetrical depolarizing and hyperpolarizing potentials, respectively. However, larger depolarizing and hyperpolarizing currents $(110$ and $160 \mathrm{pA})$ generated asymmetrical depolarizing and hyperpolarizing potentials, respectively. While the hyperpolarizing potentials increased almost linearly with increasing current intensity, the depolarizing potentials evoked by the large currents, after attaining a peak, declined to steady-state levels which were much smaller in amplitude than the hyperpolarizing potentials evoked by the same but opposite currents. This delayed rectification is clearly produced by the potassium currents observed in Fig. 3. The increase in membrane potassium conductance during large depolarizing potentials is reflected in a faster rate of repolarization upon termination of depolarizing current compared with the decay of the large hyperpolarizing potential induced by the same but opposite current. Anode break action potentials were evoked in an all-or-none manner following termination of large hyperpolarizing currents $(-110$ and $-160 \mathrm{pA})$. The small amplitudes of action potentials are most likely due to the fact that they were generated at a site remote from the soma.

\section{DISCUSSION}

Cell culture of several different cortical structures of the rat has been developed, e.g., the visual cortex (4), the hippocampus (8), and the cerebellum (9). To date, we know of no reports of primary culture of rat auditory dissociated cortical cells. Thus, we have followed standard cell culture techniques $(10,11)$ in developing the primary cell culture of rat auditory cortical neurons. Most cultures have survived for as long as 18 to 21 days. Better survival rates were obtained for the embryonic animals than for the post natal ones. After approximately three weeks in culture, some cells began to granulate, while some other cells began to die off. Under these conditions, glial overgrowth was also at times problematic.

The proliferation of neurite outgrowth of cells at early stages in culture has been also problematic, to 
say the least, for the voltage-clamp studies. Within the first few days after plating, it was at times difficult to locate cells on the cover slip that had minimal outgrowth so as to avoid space-clamp problems. Furthermore, the membrane of certain cells is at times very fragile. Neurite outgrowth, however, yield a greater number of anode-break potentials.

The results of the immunocytochemistry using two separate stains provided excellent confirmatory information. The neuron-specific marker (neuron specific enolase) and the glia-specific marker (glial fibrillary acidic protein) offered independent evidence of the identity of neurons (with prominent nuclei stained by hematoxylin) or glia, respectively. This is important because of the possibility that type 1 and type 2 astrocytes which may be present in cultures might be confused with neuronal cells.

The existence of sodium and potassium channels has been demonstrated by other investigators in different cortical (4) and non-cortical (13) cells. Of the sixteen cells that were well-clamped, all were TTX-sensitive, thus, none exhibited TTX-resistant sodium currents. This is in contrast to dorsal root ganglion cells $(13,14,15)$, striatal cells and hippocampal neurons (16) in which TTX-resistant sodium channels were found. However, our sample of cells did not cover a wide range of age nor size of cells as reported in previous investigations $(13,17)$. Therefore, the existence of TTX-resistant sodium channels in auditory cortical neurons cannot be excluded completely.

The present electrophysiologic investigation has focused on the analysis of sodium and potassium currents, since these currents are likely to be essential components for generation of action potentials in auditory cortical neurons since these neurons are excitable neocortical cells $(2,18,19)$. The currentclamp studies confirmed the regenerative nature of the neurons with small spike activity upon termination of hyperpolarizing potential response. Small amplitudes (i.e., $20 \mathrm{mV}$ ) of anode-break action potentials are probably due to the fact that they originated at a site somewhat remote from the cell body (20). The asymmetry noted between hyperpolarizing and depolarizing potentials indicate the role played by the opening of delayed rectifier potassium channels during depolarization.

\section{ACKNOWLEDGEMENTS}

We wish to extend sincere appreciation to Jonathan Bloom for expert technical assistance in electronics and computers, Philip Hockberger and Darlene Racker for superb help with photomicrography and immunocytochemistry, respectively, William Marszalec for assistance with cell culture, and Chou Wu, Jay Yeh and S. Allen Counter for many helpful discussions. The continuing support of Peter Dallos is greatly appreciated. Supported in part by an NIHNIDCD Supplement (EJM) to DC00708 (PI, Peter Dallos), and by an NIH grant NS14144 (TN).

\section{REFERENCES}

1. Zilles K. The cortex of the rat: a stereotaxic atlas. New York: Springer-Verlag, 1985.

2. Phillips DP, Reale RA, Brugge JF. Stimulus processing in the auditory cortex. In: Altschuler RA, Bobbin RP, Clopton BM, Hoffman DW, eds. Neurobiology of hearing: the central auditory system. New York: Raven Press, 1991: 335-365.

3. Moore EJ, Hall DB, Narahashi T. Rat auditory cortex neurons: Primary culture and ion channel activity. Assoc Res Otolaryngol 1994; 17: 24.

4. Baughman RW, Huettner JE, Jones KA, Khan AA. Cell culture of neocortex and basal forebrain from postnatal rats. In: Banker G, Goslin K, eds. Culturing nerve cells. Cambridge, MA: MIT Press, 1991: 22749.

5. Kelley JB. Rat auditory cortex. In: Kolb B, Tees RC, eds. The cerebral cortex of the rat. Cambridge, MA: MIT Press, 1990: 381-405.

6. Hamill OP, Marty A, Neher E, Sakmann B, Sigworth FJ. Improved patch-clamp technique for high-resolution current recording from cells and cell-free membrane patches. Pflügers Arch 1981; 391: 85-100.

7. Bezanilla F, Armstrong CM. Inactivation of the sodium channel. I. Sodium current experiments. J Gen Physiol 1977; 70: 549-66.

8. Goslin K, Banker G. Rat hippocampal neurons in low-density culture. In: Banker G, Goslin K, eds. Culturing nerve cells. Cambridge, MA: MIT Press, 1991: $251-81$.

9. Trenkner E. Cerebellar cells in culture. In: Banker G, Goslin K, eds. Culturing nerve cells. Cambridge, MA: MIT Press, 1991: 283-307.

10. Banker G, Goslin K, eds. Culturing nerve cells. Cambridge, MA: MIT Press, 1991.

11. Marszalec W, Narahashi T. Use-dependent pentobarbital block of kainate and quisqualate currents. Brain Res 1993; 608: 7-15.

12. Narahashi T. Chemicals as tools in the study of excitable membranes. Physiol Rev 1974; 54: 813-89.

13. Roy ML, Narahashi T. Differential properties of tetrodotoxin-sensitive and tetrodotoxin-resistant sodium channels in rat dorsal root ganglion neurons. J Neurosci 1992; 12: 2104-11.

14. Elliott AA, Elliott JR. Characterization of TTX-sensitive and TTX-resistant sodium currents in small cells from adult rat dorsal root ganglion. J Physiol 1993: 463: 39-56.

15. Kostyuk PG, Veselovsky NS, Tsyndrenko AY. Ionic currents in the somatic membrane of rat dorsal root ganglion neurons-I. Sodium currents. Neuroscience 1981; 6: 2423-30.

16. Hoehn K, Watson TWJ, MacVicar BA. A novel tetrodotoxin-insensitive, slow sodium current in striatal and hippocampal neurons. Neuron 1993; 10: 543-52.

17. Ogata N, Tatebayashi $H$. Ontogenic development of the TTX-sensitive and TTX-insensitive $\mathrm{Na}+$ channels in neurons of the rat dorsal root ganglia. Dev Brain Res 1992; 65: 93-100. 
18. Connors BW, Gutnick MJ. Intrinsic firing patterns of diverse neocortical neurons. Trends Neurosci 1990; 13: 99-104.

19. Wong D. Cellular organization of the cat's auditory cortex. In: Altschuler RA, Bobbin RP, Clopton BM, Hoffman DW, eds. Neurobiology of hearing: the central auditory system. New York: Raven Press, 36787.

20. Stuart G, Sakmann B. Active propagation of somatic action potentials into neocortical pyramidal cell dendrites. Nature 1994; 367: 69-72.
Received January 1, 1995; accepted February 28, 1995

Address for correspondence:

Ernest J. Moore, PhD

Department of Audiology \& Speech Sciences

Michigan State University

378 CAS Bldg.

East Lansing,

MI 48824-1212

USA

E-mail: Mooreer@Pilot.MSU.Edu 